\title{
O CORPO COMO RESPOSTA À INVOCAÇÃO DA MÃE
}

\section{Inês Catão*}

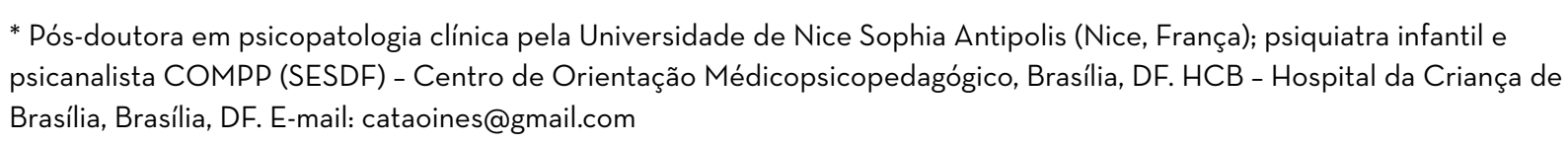

\begin{abstract}
Resumo
Afirmar a diferença entre corpo e organismo continua sendo mais que nunca necessário. Para a psicanálise, a passagem de organismo a corpo resulta do enlaçamento do registro simbólico com o registro real. Se considerarmos a transgeracionalidade do significante, seremos obrigados a considerar que o bebê sofre a influência do campo da linguagem desde antes do seu nascimento. Este fato não é sem consequências para sua vida, ao contrário, nem para a fisiologia de seu corpo e seus modos de adoecimento. Eis porque estes últimos devem ser considerados também em sua dimensão simbólica. $A$ constituição do corpo depende do laço com o Outro. O nascimento do ser humano não começa nem termina com o seu nascimento biológico. Ele é o resultado das marcas deixadas pela linguagem do Outro sobre o organismo. É a razão pela qual, em psicanálise, dizemos corpolinguagem, em uma só palavra, em lugar de dizer corpo ou organismo. No presente artigo retomamos as operações de incorporação do significante pelo viés do objeto voz. Propomos que apenas o manejo clínico da pulsão e de seus circuitos possibilita uma mudança durável na condição psicopatológica, incluindo o autismo. Palavras-chave: Psicanálise; Corpo; Voz; Autismo; Intervenção precoce.
\end{abstract}

\section{THE BODY AS A RESPONSE TO THE MOTHER'S CALL}

\begin{abstract}
Reinstate the difference between body and organism is more than ever important. To psychoanalysis, the passage from organism to body results from the intertwining of the symbolic register with the real organic. If we consider that the significants (the words) pass from one generation to another, we will be also obliged to consider that the baby suffers the influence of the language since before his birth. This fact is not without consequence for his life, on the contrary, neither for the physiology of his body and his ways of illness. That is why the latter might be considered also in the symbolic dimension. Body's constitution depends on the bond with the Other. The birth of the human being does not begin nor
\end{abstract}


finishes with biological birth. It is the result of marks left by the language of the Other over the organism. This is the reason why, in psychoanalysis, we say bodylangage in one word instead of saying body or organism. In this article, we cover the operations of incorporation of the significant from the point of view of the object voice. We suggest that only the clinic management of the drive (Trieb) and its circuits enable a durable change, in psychopathologic condition, including autism.

Key-words: Psychoanalysis; Body; Voice; Autism; Early intervention.

\section{DE ORGANISMO A CORPO: UMA CONSTITUIÇÃO}

O corpo humano é a matéria orgânica sensível ao dizer, diz Lacan no Seminário 23 O Sintoma. (1) Dar vida a este corpo é silenciar o real do organismo. Dito de outro modo, o silêncio dos órgãos é concomitante à animação do corpo. Mas, para que este se anime, é preciso fazer circular a energia psíquica, a libido. Eis o que não ocorre sem uma certa organização, sem um certo limite constituído pela referência fálica. ${ }^{(2)}$ Assim um corpo se ergue: talhado pela linguagem, costurado pelo movimento circular da pulsão e referido ao que ex-siste ao corpo: o falo.

Um corpo de significantes sozinho não faz corpo. O que é constitutivo do corpo é a organização dos significantes enquanto tais, em rede e em constante movimento de significação. Entendemos porque não é o sentido do que é dito (do que é escutado) o organizador por excelência de um corpo, mas o movimento do dizer, a enunciação. Para que esse movimento ocorra, deve se instaurar uma via de mão dupla entre o Outro primordial, encarnado pela mãe, e o bebê.

O dizer do Outro primordial dirigido à criança testemunha seu desejo, desejo de que o infans venha a falar, que ele acrescente uma palavra ao vazio da falta enunciada pela mãe. Vemos como o bebê bem pequeno movimenta todo o seu corpo insuficiente, se espreme, para tentar responder à suposição antecipada que o Outro primordial the endereça. A tentativa de fala do bebê é resposta de um corpo em vias de constituição à invocação que o Outro materno lhe faz.

O objeto pulsional voz, objeto do desejo do Outro como Lacan o descreveu, ${ }^{(3)}$ cumpre aqui seu papel primordial: pôr um corpo em movimento. E ele o faz menos pelo som e mais pelo endereçamento, sua marca essencial, como ensina Lacan. ${ }^{(3,4)}$ Supomos que o esforço que o infans faz em direção ao outro semelhante desde as primeiras horas de nascido, e que as pesquisas dos psicolinguistas atestam ser um esforço ativo, e não apenas imitativo ou responsivo, este esforço por se comunicar, é resposta à invocação significante do Outro.

Funcionamento psíquico e corpo se organizam concomitantemente. Não há um sem o outro. É o que testemunham às avessas as crianças autistas, em que a maturação e o crescimento orgânicos normais tornam insuspeitados aos desavisados um funcionamento psíquico tão particular. No autismo, um impasse extremamente precoce na estruturação do funcionamento psíquico não permite afiançar que estamos diante de um corpo.

A constituição do corpo é resposta à invocação do Outro. Como ainda não fala, o infans tenta, com seu corpo, responder ao enigma do desejo do Outro. O funcionamento inconsciente se organiza e, ao mesmo tempo, o bebê toma corpo. Suas emissões sonoras rapidamente passam a vocalizações e balbucios que ele dirige ao Outro cuidador. É assim que deixam de ser puro som. Em seu percurso 
em direção à fala, o infans caminha do som puro ao som para, como aponta Poizat. ${ }^{(5)}$ Do real do barulho à produção sonora e à alienação na musicalidade da voz do Outro há um passo, nomeado por Lacan operação de alienação.(3) Do mesmo modo, da musicalidade da voz à construção da voz enquanto objeto pulsional, há outro passo fundamental - operação de separação - que vem completar a primeira. ${ }^{(6)}$ É este o caminho que o bebê deve poder fazer para se apropriar de seu corpo e começar a falar.

A fala e o corpo são possibilidades. Porém sua efetivação supõe de um lado um Outro primordial endereçador e, do outro, um bebê receptivo e responsivo ao que lhe chega desde o campo do Outro.

\section{QUANDO A VOZ TOMA CORPO: A ENCARNAÇÃO DA LINGUAGEM}

Cabe à mãe em sua função se deixar afetar pelo que acomete o corpo do bebê, nomeando seus mal-estares em termos de necessidades como fome, sede e outros. A mãe exerce pelo bebê a capacidade de representação que ele ainda não tem constituída. Ela empresta sentido ao que lê no corpo do bebê, exercendo assim uma necessária violência interpretativa. ${ }^{(7)}$ Deste modo, a mãe serve de agente franqueador da passagem do gozo do vivo em que o organismo do bebê se encontra à sua inserção no campo da linguagem. É a identificação transitivista da mãe com o bebê que permite as primeiras inscrições constituintes do psiquismo da pequena criança.

O bebê captura o modo de gozo materno através do seu olhar e de sua voz. O gozo da mãe cumpre uma função constitutiva para o bebê. Ele deve poder tomar-se pelo objeto deste gozo. Assim o bebê encontra um convite à alienação no campo do Outro. Aceitando alienar-se o bebê poderá, $a$ posteriori, apropriar-se da representação do vivido forjada pela mãe tornando-a sua.

É a mãe quem sustenta para o bebê a incorporação do significante. Ela costura o campo da linguagem ao real do corpo da criança. E ela o faz por meio de sua voz. A mãe fala com ele e por ele. O bebê chama, é chamado e se faz chamar respondendo à invocação e demonstrando, deste modo, sua implicação no gozo do Outro. Não basta que haja gozo materno. É preciso uma implicação do bebê. Eis deste modo instaurado o circuito da pulsão invocante, experiência que serve de primórdio à estruturação do inconsciente como uma linguagem.

\section{LENDO O CORPO DO BEBÊ: A INSCRIÇÃO PRECOCE DO SOFRIMENTO PSÍQUICO}

A clínica com o bebê testemunha a diferença entre organismo e corpo.' Sem ter ainda constituído a possibilidade de fala, o bebê inscreve no real da carne seu sofrimento psíquico. É preciso aprender a ler os sinais de sofrimento do bebê para intervir o mais a tempo possível. Este é um imperativo ético. Não é preciso aguardar a cristalização dos sintomas em um corpo que dá sinais de seu sofrimento, antes de intervir.

Em seu livro A Clínica Precoce, Graciela Crespin propõe um inventário de sinais positivos do desenvolvimento - aqueles que testemunham que os processos psíquicos subjacentes estão funcionando como o previsto -, e propõe duas séries de sinais indicadores de sofrimento psíquico precoce - série barulhenta e série silenciosa - a última mais grave por passar despercebida. ${ }^{(8)}$ Para propor tais sinais, a autora baseou-se nos três grandes registros pulsionais do primeiro ano de vida. Assim, em relação à oralidade, Crespin afirma que "a satisfação pulsional parece mesmo tão central que sua ausência pode entravar a satisfação da própria necessidade alimentar."(8) Não podemos esquecer a dimensão simbólica quando estamos diante de recusas alimentares ativas, refluxos e vômitos recidivantes e resistentes à maturação e aos tratamentos clássicos. Menos frequente, a anorexia grave do lac-

\footnotetext{
Winnicott foi o pediatra que tirou consequências desta diferença que sua prática clínica apontou. Elas estão nos inúmeros escritos que deixou, por exemplo, no artigo de 1949 "A mente e a sua relação com o psique-soma".
} 
tente encontra-se na mesma série, barulhenta, não devendo ser tratada apenas como uma urgência médica. Fazem parte da série silenciosa o preenchimento passivo e as síndromes bulímicas.

Em relação ao registro pulsional da especularidade, a autora lista como série barulhenta o evitamento seletivo do olhar e, como silenciosa, a não fixação do olhar (o olhar que não se direciona), a persistência do estrabismo fisiológico e o nistagmo. Quanto à pulsão invocante, são sinais da série barulhenta a persistência de gritos inarticulados para além do período neonatal, e a inconsolabilidade do bebê. Silenciosa é a cessação do apelo.

Os distúrbios do sono e do registro tônico-postural são também indicadores sensíveis da qualidade do laço do bebê com o Outro cuidador. São distúrbios barulhentos todos os distúrbios do sono como as dificuldades de adormecimento e o despertar noturno com ou sem relato de pesadelos. Da série silenciosa fazem parte a hiperssonia ou a insônia calma do bebê. Crespin aponta a importância de levar em conta o diálogo tônico-postural entre a mãe e o bebê. São barulhentos as hipotonias e hipertonias, e também os atrasos psicomotores, mesmo se inseridos num quadro neurológico declarado. Silenciosos são os balanceios e os detonadores de estereotipias, francamente instalados apenas no curso do segundo ano de vida, antes das automutilações.

As pesquisas clínicas nos permitem constatar hoje que os sinais de sofrimento psíquico estão presentes desde muito mais cedo do que supúnhamos e que, negligenciados, vão se cristalizando em sintomas mais e mais evidentes.

Samuel foi um extremo prematuro. Nasceu com 26 semanas e 3 dias de gestação. Pesava 730 gramas. Sua mãe, obesa, casada a 9 anos, muito embora desejasse ter um bebê, surpreendeu-se ao descobrir que estava grávida 15 dias antes do seu nascimento. Atribuía seus mal-estares corporais a outras motivações, mesmo estando em idade fértil e não fazendo prevenção de uma possível gravidez. Samuel nasceu de parto normal, mas apresentou várias complicações neonatais que o retiveram na U.T.I. neonatal por cerca de 3 meses. Com 3 meses de nascido, seu pai foi quem primeiro notou que o bebê não o olhava. A mãe atribuiu o comentário do marido aos defeitos que este e sua sogra tentavam pôr em seu filho. Ela não percebia o não olhar de seu filho. Diz, chorando, que tinha muito medo de descobrir que ele tivesse algum problema. A pediatra encaminhou Samuel para a Educação Precoce ${ }^{2}$ e para a neurologista. Esta, diante dos transtornos do olhar do bebê, solicitou um Potencial Evocado Visual (PEV). Sua tomografia de crânio mostrou-se bastante alterada. O bebê apresentava alterações ao exame neurológico que levaram a neuropediatra a fazer uma primeira hipótese de Paralisia Cerebral. Samuel não foi encaminhado a nenhum serviço especializado de Saúde Mental.

Foi em busca do exame solicitado pela neurologista, exame que não fazemos em nosso serviço, ${ }^{3}$ que Samuel chegou até nós. Aos 8 meses de idade 4 era fisicamente um pequeno bebê hipertônico, que não se acomodava ao colo de sua mãe, não sustentava a cabeça e ainda não sentava. Não era capaz de pegar objetos e mantinha as mãos fechadas, o que preocupava a mãe. Não sorria e não balbuciava, apenas chorava às vezes, sendo inconsolável. Não demonstrava qualquer interesse particular pela presença do outro. Ao contrário, como o pai bem havia notado, não-fixava o olhar. A neurologista constatou a presença de refluxo gastroesofágico. A mãe negou a informação e não deu o remédio prescrito. ${ }^{5}$ Aos 10 meses, ${ }^{6}$ Samuel passou a apresentar espasmos e irritabilidade que levaram a neuropediatra a fazer a hipótese de Síndrome de West, síndrome neurológica de prognóstico grave, que cursa em $45 \%$ dos casos com um quadro de autismo. ${ }^{7}$

Além do exame neurológico alterado, o corpo de Samuel dá mostras inequívocas de sua insustentabilidade psíquica indicando que, além do trata-

\footnotetext{
2 Programa da SEEDF.

3 O serviço referido é o COMPP. Centro de Orientação Médicopsicopedagógica (SES-DF).

4 Idade corrigida 5 meses.

5 A neuropediatra prescreveu Bromoprida.

7 meses de idade corrigida.

Segundo Laznik, em 90\% dos casos de Síndrome de West que cursam com autismo, o sinal PREAUT dos 9 meses mostra-se positivo, ou seja, sensível para a detecção deste risco .
} 
mento medicamentoso com anticonvulsivantes e de estimulação, é imperiosa a chamada Intervenção Precoce por um profissional capacitado para tal. Mesmo se a intervenção dita precoce chega sempre tarde demais, como neste caso.

$\mathrm{Na}$ clínica precoce, trata-se de escutar a mãe e ler o corpo do bebê. Diferente da observação de bebês trata-se aqui de uma operação de leitura. $\mathrm{O}$ bebê deve ser tomado ao pé da letra. Trata-se de elevar o real de seu corpo à condição de enigma, de cifra de sua relação com o Outro primordial. Essa leitura clínica não busca compreender e interpretar o sentido, mas operar com a cifra sob transferência, dando ao bebê a possibilidade de transformação frente ao que o acomete no real de seu corpo. ${ }^{(9)}$ Relembrando Lacan, o corpo humano é a matéria orgânica sensível ao dizer.

\section{A CRIANÇA AUTISTA: UM ORGANISMO QUE RESISTE A TORNAR-SE CORPO}

Por razões que ainda desconhecemos, o bebê que posteriormente receberá o diagnóstico de autismo: não responde à invocação que lhe chega do campo do Outro, ou responde fracamente ou não responde do mesmo modo que a maioria dos bebês. Ao contrário da maior parte dos bebês, o bebê futuro autista não revela uma implicação no gozo do Outro. ${ }^{(10)}$

A recusa em tomar-se pelo objeto de gozo do Outro faz fracassar o necessário estabelecimento do laço. A criança autista encontra-se no campo da linguagem, mas fora do discurso. Sua estruturação psíquica insuficiente ou, como querem alguns, enodada de um outro modo, deixa a meio caminho o laço com o Outro. Nossa experiência clínica nos leva a pensar que a criança autista quer este laço como a maioria das crianças. Mas ela encontra-se mal aparelhada para o exercício da vocação de todo humano, qual seja, estar em relação transferencial com a alteridade.
Um fracasso no estabelecimento dos circuitos pulsionais - em que o terceiro tempo da pulsão não se estabelece, segundo a hipótese de Laznik ${ }^{(11)}$ -, resulta em um corpo que, se não é "apenas" matéria orgânica, não se sustenta enquanto corpolinguagem. As operações de inscrição do simbólico no real orgânico - alienação e separação -, não se completam, comprometendo a constituição do registro do imaginário e a efetivação do funcionamento psíquico de modo habitual.

\section{POR UM DESENVOLVIMENTO PSÍQUICO SUSTENTÁVEL}

Neste artigo, sublinhamos a importância de pensar o desenvolvimento infantil mais além da maturação e do crescimento, visíveis e facilmente mensuráveis, mas insustentáveis, como vimos, sem o desenvolvimento psíquico. De materialidade pouco evidente e início extremamente precoce, o desenvolvimento psíquico implica operações sutis que ocorrem em tempos lógicos, ainda que não desconheçam a cronologia. E, sobretudo, depende da instauração de um laço com o Outro primordial.

Os quadros psicopatológicos da infância, sobretudo os mais graves - autismos e psicoses da infância-, decorrem de impasses nos tempos lógicos da estruturação psíquica. Eis a razão pela qual uma abordagem terapêutica de efeitos duráveis, em termos subjetivos, deve levar em conta o modo como o funcionamento psicopatológico se constituiu. Estes impasses comprometem o funcionamento dos circuitos pulsionais como o previsto, produzindo sintomas que dificultam, ou até mesmo impedem, o desenvolvimento psíquico da criança. É pelo manejo clínico de tais circuitos, partindo do que a criança produz, que o psicanalista busca relançar o movimento estruturante precocemente interrompido. O que se busca como resultado não é a normatização da criança, mas que esta possa se constituir como sujeito e ator de sua própria vida, capaz de utilizar todas as suas potencialidades. 
Nosso modus vivendi das últimas décadas parece querer desconhecer o que há de particular em nossa humanidade. As propostas que apontam para cada sintoma um remédio e que visam a mudança comportamental das crianças sem escutá-las, seu brincar funcional, não serão sem consequências para as próximas gerações. Não estaríamos diante do resultado na clínica de um crescimento econômico que não leva em conta a possibilidade de esgotamento de recursos naturais e o consequente comprometimento das gerações futuras, um crescimento em que os fins justificam os meios?

\section{REFERÊNCIAS}

1. Lacan J. O Seminário, livro 23: o sinthoma. Rio de Janeiro: Zahar; 1975-1976/2007.

2. Melman $C . L^{\prime}$ inconscient, $c$ 'est I'organique. Le Trimestre Psychanalytique $\mathrm{n}^{\circ} 2$ Le Corps, publication de I'Association freudienne. 1991.

3. Lacan J. O Seminário, livro 11: os quatro conceitos fundamentais da psicanálise. Rio de Janeiro: Zahar; 1964/1985.

4. Lacan J. O Seminário, livro 10: a angústia. Rio de Janeiro: Zahar; 1962-63/2005.
5. Poizat M. L'Opéra ou le Cri de I'ange. Essai sur la jouissance de l'amateur d'opéra. Paris: Métailié; 1986.

6. Catão I. Do som à música, da música à voz: os passos da fundação do sujeito. In: Atem LM, editor. Cuidados no início da vida. São Paulo: Casa do Psicólogo; 2008.

7. Aulagnier P. A violência da interpretação: do pictograma ao enunciado. Rio de Janeiro: Imago; 1979.

8. Cullere-Crespin G. A clínica precoce: o nascimento do humano. São Paulo: Casa do Psicólogo; 2004.

9. Jerusalinsly J. A criação da criança: brincar, gozo e fala entre a mãe e o bebê. Salvador: Ágalma; 2011.

10. Laznik M-C, Maestro, S, Muratori, F, ParlatoOliveira, E. Les interactions sonores entre les bébés devenus autistes et leurs parents. In: Castarède MF, Konopczynski G, editors. Au commencement était la voix. Ramonville SaintAgnes: Ėrès; 2005.

11. Laznik M-C. A voz da sereia: o autismo e os impasses na constituição do sujeito. Salvador: Ágalma; 2004. 